\title{
Operant generalization of auditory tempo in quail neonates
}

\author{
SUSAN M. SCHNEIDER AND ROBERT LICKLITER \\ Florida International University, Miami, Florida
}

\begin{abstract}
Operant generalization, a building block of cognition, has never been studied in neonates. We developed a preparation for newly hatched quail in order to investigate the form of the generalization gradient very early in development. For their first 4-5 days after hatching, northern bobwhite chicks pecked for brief heat presentations while hearing a high-pitched sound repeated at a constant rate (nondifferential training). Tempo generalization was then assessed in extinction. A significantly excitatory average gradient resulted despite minimal postnatal experience.
\end{abstract}

As a fundamental component of both learned and unlearned behavior and cognition, generalization has been extensively studied. In a review, Ghirlanda and Enquist (2003) concluded that generalization operates similarly across operant, respondent, and species-typical behaviors, and across a wide range of variables. Nevertheless, some basic questions about the provenance and range of generalization remain.

One of the earliest generalization research topics concerned the role of nature-nurture relations. Was experience necessary for the discrimination that produced peaked gradients, and if so, how much experience and of what sort? Even in adults, that story appears to be a complicated one. In juveniles, differential (differently consequated) exposure to a stimulus dimension has appeared essential for peaked results in some cases (e.g., Kerr, Ostapoff, \& Rubel, 1979; Peterson, 1962; Rubel \& Rosenthal, 1975) but not in others (e.g., Ganz \& Riesen, 1962; Malott, 1968; Mountjoy \& Malott, 1968; Rudolph \& Honig, 1972; Rudolph, Honig, \& Gerry, 1969).

To date, the literature on generalization in the first week of independent life appears to be restricted to habituation or classical conditioning preparations, although avian and mammalian newborns are known to be capable of operant behavior and operant learning (e.g., Delsaut, 1991, for 1-day-old chicks; Flory, Langley, Pfister, \& Alberts, 1997, for 1-day-old rats). Thus, the major aim of the present study was to investigate the nature of operant generalization in neonates, with their very minimal experience. The younger the age at which generalization gradients are obtainable, the better our ability to study their provenance and development. To meet this goal, we developed a new preparation utilizing heat reinforcement in precocial quail neonates.

We studied temporal generalization, which has unusual properties due to the presence of timing as well as of memorial and perceptual processes (see, e.g., Russell \& Kirkpatrick, 2007; Wearden \& Lejeune, 2008). Humans respond to auditory tempo as a characteristic critical for language and musical participation. Discrimination of the temporal characteristics of songs and calls is also critical for many species of birds, including quail (see, e.g., Gottlieb, 1971; Heaton, Miller, \& Goodwin, 1978; Kroodsma, 2005; Stokes, 1967). The young northern bobwhite (Colinus virginianus) in this study are no exception, and pilot testing showed that, even immediately following hatching, this quail species can discriminate between slight differences in the tempo of a repeated maternal call.

Auditory tempo generalization has been the subject of only a few studies. Crites, Harris, Rosenquist, and Thomas (1967) produced one of the first, showing peaked operant generalization to click rate in rats after differential training. However, Farthing and Hearst (1972) found that pigeons trained nondifferentially with click frequency produced flat gradients, and Weiss and Schindler (1981) made a similar finding for rats (see also Hearst, 1965; Williams, 1973).

With respect to psychophysics, using classical conditioning of respiration suppression in goldfish, Fay (1994) showed that pulse trains at fast tempos produced monotonic gradients and suggested an absolute-interval basis as primary. ${ }^{1}$ Hulse and Kline (1993) trained European starlings on a two-choice discrimination between two sets of two different pure-tone pulse rates, then observed response proportions on the two choices when novel, intermediate pulse rates were presented. Weber's law held (see also Lejeune, 1990; but cf. Bizo, Chu, Sanabria, \& Killeen, 2006), and an analysis of the bisection points showed a generalization basis somewhat closer to an average-rate basis than to an absolute-interpulse-interval basis. However, in a similar study with rats, Meck, Church, and Olton (1984) reported an absolute-interval basis instead. 
Accordingly, in the present study, we set equal absolute intervals between the test points in our generalization assessment. Given our knowledge of operant/speciestypical interactions (see, e.g., Ghirlanda \& Enquist, 2003; Schneider, 2003), we created what we expected would be a salient auditory stimulus with some ecological validity: an artificial beep containing two of the dominant frequencies and some of the overtones found in a typical northern bobwhite maternal assembly call. This call is highly attractive to the chicks (e.g., Heaton et al., 1978; Lickliter \& Virkar, 1989). We attempted to obtain generalization gradients for auditory tempo after nondifferential training during the chicks' first 4-5 days after hatching.

\section{METHOD}

\section{Subjects}

We hatched commercially supplied fertilized northern bobwhite eggs in our lab, limiting prenatally heard sounds to background noise and the vocalizations of broodmates. Following hatching, chicks were reared socially in a sound-attenuated rearing room, in bins $(430 \times$ $250 \times 150 \mathrm{~mm}$ ) containing chicks of the same age, with free access to food and water. Again, chicks heard only background noise and the vocalizations of their broodmates. The chicks weighed only 6 to $7 \mathrm{~g}$ upon hatching and were capable of only limited thermoregulation (see, e.g., Borchelt \& Ringer, 1973). As a result, they required rich schedules of heat reinforcement in the operant chamber.

The northern bobwhite is a highly social species at all stages of life (Stokes, 1967). In order to minimize the stress of isolation in the operant chamber, a fuzzy surrogate of chick-like size, texture, and color pattern was placed in each rearing room in bins. A surrogate was also present in the back of the operant chamber throughout testing.

\section{Apparatus}

An infrared "touchscreen" detection frame (Elotouch Extended Resolution) was attached to a 380-mm (15-in.) flatscreen monitor. The touchscreen was programmed in Visual Basic to record pecks in a demarcated target area. Because the monitor warmed during the sessions, a double layer of 2.2-mm acrylic sheeting was inserted as insulation between the touchscreen frame and the bottom half of the monitor, and the chicks pecked the acrylic. A photobeam array was set at $8.3 \mathrm{~mm}$ from the acrylic cover, a distance that allowed the chicks' beaks to signal a touch. ${ }^{2}$

The top and one long side were removed from a cardboard box that measured $330 \times 180 \times 180 \mathrm{~mm}$. The short sides of this operant chamber fitted snugly along the frame of the touchscreen, so the chicks could approach the entire lower monitor display. At the bottom edge of the touchscreen detection area, an acrylic sheet over the box floor was covered by the shelf liner also used in the rearing bins. Both the operant chamber and the rearing bins had wire mesh lids.

Computer speakers were placed on either side of the operant chamber, about $2 \mathrm{~cm}$ in front of the monitor. The auditory stimulus was the repeated $90-\mathrm{msec}$ beep described above, with an interbeep interval of $229 \mathrm{msec}$, played at a volume of $75 \mathrm{~dB}$. Sound spectrogram analysis verified that the two dominant frequencies in the beep were approximately $700 \mathrm{~Hz}$ and $2800 \mathrm{~Hz}$, both in the higher sensitivity audibility range for the species (Barton, Bailey, \& Gatehouse, 1984), accompanied by lower-volume overtones.

The apparatus was enclosed within a sound-attenuating cubicle (Med Associates, inside dimensions of $559 \times 559 \times 356 \mathrm{~mm}$ ). This cubicle and the controlling computer were in turn housed inside a completely partitioned enclosure.

\section{Procedure}

Autoshaping. An autoshaping procedure was used to establish target pecking. The target was a white rectangle of $105 \times 50 \mathrm{~mm}$, its bottom edge $8 \mathrm{~mm}$ above the bottom edge of the screen, centered on a dark red background. The target appeared and disappeared in a 10 -sec-on/10-sec-off pattern. At the end of the 10-sec target-on period, $0.3 \mathrm{sec}$ of heat was delivered from a $250-\mathrm{W}$ white heat lamp suspended over the chick's pecking position. A peck to the target immediately caused the target's disappearance and activated the heat lamp, accompanied by a relay click. After the first 4 pecks, the autoshaping sequence ended, the target remained on, and a continuous reinforcement schedule took effect. When fewer than 10 pecks had accumulated, a responding pause of more than $30 \mathrm{sec}$ started the 10 -sec/10-sec autoshaping sequence again. After 25 pecks, a variable ratio (VR) 1.25 replaced the continuous schedule and stayed in effect for the remainder of the session. (Note that this means that on average, 8 of every 10 pecks were reinforced, because .8 is the inverse value) A constant-probability method of scheduling was used. The VR schedule included two additional components that were found to enhance responding. First, if an interresponse time greater than $10 \mathrm{sec}$ occurred, the peck that ended it was always reinforced. Second, a differential-reinforcement-of-high-rate feature provided reinforcement for all pecks with interresponse times shorter than $1.5 \mathrm{sec}$.

During the 15 -min autoshaping session, $82 \%$ of the chicks pecked at least once; most of these pecked between 30 and 200 times. All of the chicks that pecked at least 30 times participated in the training sessions, and some that pecked in the range of 1-30 were also included. (No noticeable differences occurred as a result of lower autoshaping rate, except for a somewhat decreased likelihood of completing the study.) The chamber temperature was adjusted according to the chick's weight. Autoshaping sessions were run at about $24 \mathrm{~h}$ of age.

In order to enhance the likelihood of response acquisition and maintenance, all target pecks produced both auditory and visual feedback. After the four autoshaped pecks that completed the autoshaping sequence, the visual consequence was a brief 0.2 -sec blink-off of the target. To avoid introducing an additional sound, the auditory feedback was the same beep used in the training stimulus. ${ }^{3}$ The training stimulus sounded whenever the target was present during autoshaping and continuously during the training sessions.

Training. Each chick was tested twice each day for 3-5 days (see below). Over sessions, intermittent schedules of VR 1.18 or 1.25 (that is, taking the inverse, reinforcement proportions of .8 to .85 ) were leaned to a final VR 1.33 (a reinforcement proportion of .75). On this schedule, a tighter differential-reinforcement-of-high-rate contingency was used, so that pecks with interresponse times shorter than $1 \mathrm{sec}$, rather than $1.5 \mathrm{sec}$, were always reinforced.

Initial temperatures in the operant chamber continued to be set on the basis of chick weight, in an attempt to produce equivalent motivation levels. Toward this end, we attempted to run at the highest temperature that produced sufficient motivation for a reasonable response rate (the cost of this approach being a higher attrition rate).

Generalization test. The first $5 \mathrm{~min}$ of the generalization test was normal VR 1.33 training. The last 10.5 min consisted of 10 presentations each in extinction of seven different beep rates, each lasting $8.5 \mathrm{sec}$ and followed by a 0.5 -sec pause. (Any responses during that brief pause were attributed to the stimulus that had just ended.) Each of the seven interbeep intervals differed from the next by the same absolute difference in spacing: $30 \mathrm{msec}$. The beep, which always lasted $90 \mathrm{msec}$, was followed by a different interval of silence for each tempo. For the slowest tempo, Interbeep Interval 1 was $319 \mathrm{msec}$ of silence; for the fastest, Interbeep Interval 7 was $139 \mathrm{msec}$. The training tempo included a 229 -msec period of silence (Interbeep Interval 4). The seven beep rates occurred without replacement in random order, cycle by cycle for 10 cycles. In this session, the feedback beep for responding was discontinued. In this paradigm, each chick receives only one generalization test.

In order to ensure a sufficient sample size, data were used only when a chick responded at least 75 times during the 10.5-min generalization test (i.e., over 7.0 responses per minute). Despite our use of neonates and our running the experiment at relatively warm temperatures, $62 \%$ of the 26 chicks that started training met the generalization test response requirement. 
We thus obtained 16 gradients. Of these, at least 3 chicks were at each of four training levels: five, six, seven, or eight postautoshaping sessions. However, the results proved to be similar across training levels and were simply combined. All of the chicks were either 96 or $120 \mathrm{~h}$ old at the time of the generalization test; again, no differences were observed as a function of this variable.

\section{RESULTS}

Figure 1 shows the average absolute and relative generalization gradients for the 16 chicks that met the generalization test response requirement. The relative results are based on the proportion of responding at each test stimulus, rather than on the absolute response rates: Any individual gradient thus has the same shape when presented in either form, but averaged absolute and relative gradients are seldom identical to each other, and those in this experiment were no exception. The relative method of presentation eliminated the bias otherwise introduced

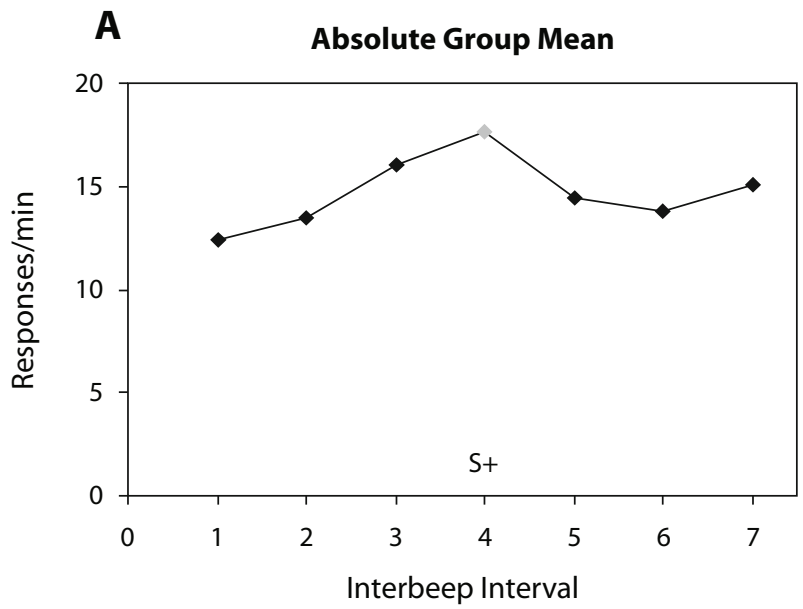

B

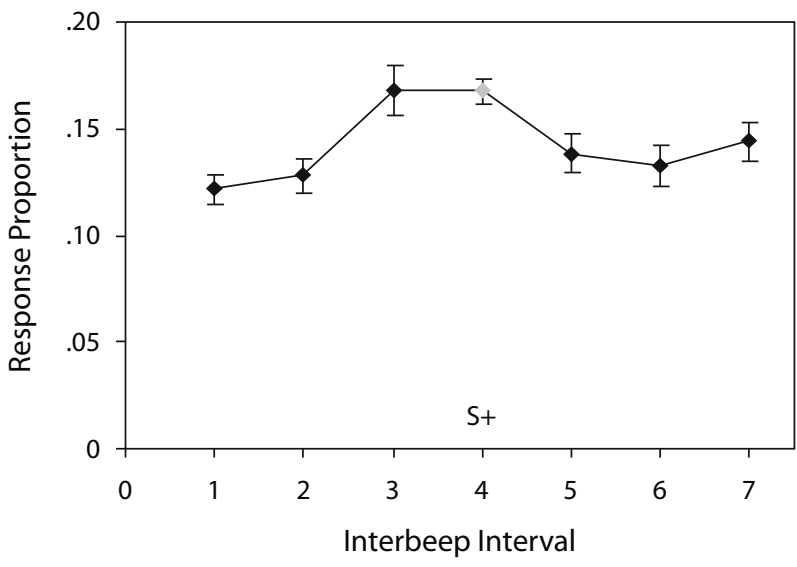

Figure 1. Group mean generalization gradients. (A) Absolute gradient. (B) Relative gradient with standard error bars. Interbeep intervals differed by a constant increment of $30 \mathrm{msec}$ of silence. Interbeep Interval 1 was the longest, at 319 msec (thus corresponding to the slowest beep rate); Interbeep Interval 7 was the shortest, at 139 msec. At 229 msec, Interbeep Interval 4 was the training stimulus (indicated on the $x$-axis and by a gray point). by, in this case, 3 chicks that responded at unusually high rates of about 30 responses per minute; the average generalization test response rate was 14.7 responses per minute. (For the same reason, as is typical for this type of research, no variability measure is provided for the average absolute results.) Both gradients appear to be weakly excitatory. A one-way repeated measures ANOVA on the absolute data revealed significant differences in responding to the different test stimuli $[F(6,90)=4.34, p<.001]$. Tukey's post hoc test showed significant differences between the training stimulus peak and the values at Interbeep Intervals 1,2 , and $6(p<.05)$. A parametric test was not appropriate for the relative data, but a Friedman test showed significant results $\left(\chi^{2}=20.8, p<.005\right)$.

\section{DISCUSSION}

We provided nondifferential training with a constant auditory tempo to quail neonates before testing for tempo generalization in extinction. Both the absolute and relative average gradients were weakly excitatory. To the best of our knowledge, this is the youngest age at which operant generalization gradients have been obtained.

The shallow average relative gradient was consistent with some of those produced by adult animals - for example, with pigeons for auditory frequency after nondifferential training to a tone (Jenkins \& Harrison, 1960). After more extensive training on a leaner food reinforcement schedule, the 3 pigeons produced an average gradient almost identical to that of the chicks in the present study; indeed, Jenkins and Harrison found that the level of training did not affect the shape of the gradient. On the basis of our results, excitatory operant generalization of this magnitude may not require significant postnatal experience of any sort.

Our birds produced average gradients that were notably more peaked than the flat gradients found in adult pigeons and rats after nondifferential click frequency training (Farthing \& Hearst, 1972; Weiss \& Schindler, 1981). Perhaps the complex tone that we used was more salientas it was designed to be-with corresponding effects on the gradients. Rilling (1977) concluded that the critical variables affecting operant nondifferential gradient shape include the stimulus dimension and the species (and the same may apply to habituation and classical conditioning paradigms; Ghirlanda \& Enquist, 2003). The richness of the reinforcement schedule may also have helped produce excitatory rather than flat gradients (see, e.g., Hearst, Koresko, \& Poppen, 1964; Thomas \& Switalski, 1966).

Nondifferential gradients-always flatter than corresponding differential gradients - can nonetheless be steeply peaked under ideal circumstances. In the present novel preparation, although the quail chicks are strongly sensitive to auditory stimuli (e.g., Barton et al., 1984; Heaton et al., 1978), we lacked a correlated visual cue to counteract the constant presence of the white target rectangle. The relative salience of the training stimulus compared with that of other contextual stimuli has been shown to influence the slope of the gradient: In the manner of classical conditioning, when a number of stimuli 
are predictive of an unconditioned stimulus, whatever is salient can become conditioned. For pigeons, use of a lighted key in both training and testing has been shown to mask stimulus control by the training stimulus, making operant generalization responding flatter than it otherwise would have been (see Mackintosh, 1977, for a discussion; also see Rudolph \& van Houten, 1977).

With respect to the psychophysics of tempo generalization, the two fastest beep rates (Interbeep Intervals 6 and 7) were the easiest to discriminate, with a Weber fraction of $22 \%$, compared with $10 \%$ for the two slowest rates. ${ }^{4}$ The fact of its easy discrimination may have contributed to the nonmonotonic results seen in several chicks at Interbeep Interval 7, reflected in the shape of the average gradients in Figure 1 and in the post hoc statistical analysis. As noted by Honig and Urcuioli (1981), such changes in discriminability can affect the symmetry of a gradient (see also Ghirlanda \& Enquist, 2003, and, e.g., Walker \& Branch, 1998, for other examples of such nonmonotonic results, a phenomenon seen with some regularity). In this particular preparation, another possibility is the increase in sheer auditory density, making the dimension reminiscent of an intensity-based spectrum like acoustic volume. Ghirlanda and Enquist noted that intensity-based gradients are qualitatively different from gradients based on other dimensions, because higher intensity often evokes more responding regardless of the position of the training stimulus (see Meltzer, Masaki, \& Niebuhr, 1973). The average gradients are symmetrical apart from the upturn at the extremity, but at this stage, speculation about the psychophysical basis for this generalization appears premature. The same caution must be applied to speculation about its provenance (cf. Campbell \& Haroutunian, 1983; Kerr et al., 1979), but we have established the existence of typical nondifferential excitatory results after our subjects had little more than an hour of experience.

\section{AUTHOR NOTE}

This research was supported by NIMH Grant RO1-62225 and NICHD Grant RO1-048423 (to R.L.). We thank Christian Krägeloh for his helpful comments on a previous version of the article. Correspondence concerning this article should be addressed to S. M. Schneider, Department of Psychology, Florida International University, Miami, FL 33199 (e-mail: schneids@fiu.edu).

\section{REFERENCES}

Barton, L., Bailey, E. D., \& Gatehouse, R. W. (1984). Audibility curve of bobwhite quail (Colinus virginianus). Journal of Auditory Research, 24, 87-97.

Bizo, L. A., Chu, J. Y. M., Sanabria, F., \& Killeen, P. R. (2006). The failure of Weber's law in time perception and production. Behavioural Processes, 71, 201-210.

Borchelt, P., \& Ringer, R. K. (1973). Temperature regulation development in bobwhite quail (Colinus virginianus). Poultry Science, 52, 793-798.

Campbell, B. A., \& Haroutunian, V. (1983). Perceptual sharpening in the developing rat. Journal of Comparative Psychology, 97, 3-11.

Crites, R. J., Harris, R. T., Rosenquist, H., \& Thomas, D. R. (1967). Response patterning during stimulus generalization in the rat. Journal of the Experimental Analysis of Behavior, 10, 165-168.

Delsaut, M. (1991). Influence of nonobvious learning on the development of the approach response in chicks (Gallus gallus). International Journal of Comparative Psychology, 4, 239-251.

Farthing, G. W., \& Hearst, E. (1972). Stimulus generalization and discrimination along the click-frequency (flutter) continuum in pigeons. Perception \& Psychophysics, 12, 176-182.

FAY, R. R. (1994). Perception of temporal acoustic patterns by the goldfish (Carassius auratus). Hearing Research, 76, 158-172.

Flory, G. S., Langley, C. M., Pfister, J. F., \& Alberts, J. R. (1997). Instrumental learning for a thermal reinforcer in 1-day-old rats. $D e$ velopmental Psychobiology, 30, 41-47.

Ganz, L., \& Riesen, A. H. (1962). Stimulus generalization to hue in the darkreared macaque. Journal of Comparative \& Physiological Psychology, 55, 92-99.

Ghirlanda, S., \& ENQuist, M. (2003). A century of generalization. Animal Behaviour, 66, 15-36.

Gottlieb, G. (1971). Development of species identification in birds: An inquiry into the prenatal determinants of perception. Chicago: University of Chicago Press.

Hearst, E. (1965). Approach, avoidance, and stimulus generalization. In D. I. Mostofsky (Ed.), Stimulus generalization (pp. 331-355). Stanford: Stanford University Press.

Hearst, E., Koresko, M. B., \& Poppen, R. (1964). Stimulus generalization and the response-reinforcement contingency. Journal of the Experimental Analysis of Behavior, 7, 369-380.

Heaton, M. B., Miller, D. B., \& Goodwin, D. G. (1978). Speciesspecific auditory discrimination in bobwhite quail neonates. Developmental Psychobiology, 11, 13-21.

Honig, W. K., \& Urcuioli, P. J. (1981). The legacy of Guttman and Kalish (1956): 25 years of research on stimulus generalization. Journal of the Experimental Analysis of Behavior, 36, 404-445.

Hulse, S. H., \& Kline, C. L. (1993). The perception of time relations in auditory tempo discrimination. Animal Learning \& Behavior, 21, 281-288.

Jenkins, H. M., \& Harrison, R. H. (1960). Effect of discrimination training on auditory generalization. Journal of Experimental Psychology, 59, 246-253.

Kerr, L. M., Ostapoff, E. M., \& Rubel, E. W. (1979). Influence of acoustic experience on the ontogeny of frequency generalization gradients in the chicken. Journal of Experimental Psychology: Animal Behavior Processes, 5, 97-115.

Klump, G. M., \& MAIER, E. H. (1989). Gap detection in the starling (Sturnus vulgaris): I. Psychophysical thresholds. Journal of Comparative Physiology A, 164, 531-538.

Kroodsma, D. (2005). The singing life of birds: The art and science of listening to birdsong. Boston: Houghton Mifflin.

LeJEune, H. (1990). Timing: Differences in continuity or generality beyond differences? In D. E. Blackman \& H. Lejeune (Eds.), Behaviour analysis in theory and practice: Contributions and controversies (pp. 53-90). Hillsdale, NJ: Erlbaum.

LICKLITER, R., \& VIRKAR, P. (1989). Intersensory functioning in bobwhite quail chicks: Early sensory dominance. Developmental Psychobiology, 22, 651-657.

Mackintosh, N. J. (1977). Stimulus control: Attentional factors. In W. K. Honig \& J. E. R. Staddon (Eds.), Handbook of operant behavior (pp. 481-513). Englewood Cliffs, NJ: Prentice Hall.

Malotт, M. K. (1968). Stimulus control in stimulus-deprived chickens. Journal of Comparative \& Physiological Psychology, 66, 276-282.

Meck, W. H., Church, R. M., \& Olton, D. S. (1984). Hippocampus, time, and memory. Behavioral Neuroscience, 98, 3-22.

Meltzer, D., Masaki, M. A., \& Niebuhr, B. R. (1973). Click frequency as a stimulus intensity parameter. Bulletin of the Psychonomic Society, 1, 135-136.

Mountjoy, P. T., \& Malott, M. K. (1968). Wavelength generalization curves for chickens reared in restricted portions of the spectrum. Psychological Record, 18, 575-583.

Peterson, N. (1962). Effect of monochromatic rearing on the control of responding by wavelength. Science, 136, 774-775.

RiLling, M. (1977). Stimulus control and inhibitory processes. In W. K. Honig \& J. E. R. Staddon (Eds.), Handbook of operant behavior (pp. 432-480). Englewood Cliffs, NJ: Prentice Hall.

Rubel, E. W., \& Rosenthal, M. H. (1975). The ontogeny of auditory frequency generalization in the chicken. Journal of Experimental Psychology: Animal Behavior Processes, 1, 287-297.

RudolPH, R. L., \& HoNIG, W. K. (1972). Effects of monochromatic rearing on spectral discrimination learning and the peak shift in chicks. Journal of the Experimental Analysis of Behavior, 17, 107-111. 
Rudolph, R. L., Honig, W. K., \& GerRy, J. E. (1969). Effects of monochromatic rearing on the acquisition of stimulus control. Journal of Comparative \& Physiological Psychology, 67, 50-57.

RUdOLPH, R. L., \& VAN Houten, R. (1977). Auditory stimulus control in pigeons: Jenkins and Harrison (1960) revisited. Journal of the Experimental Analysis of Behavior, 17, 107-111.

Russell, R., \& KirkPATRicK, K. (2007). The role of temporal generalization in a temporal discrimination task. Behavioural Processes, $\mathbf{7 4}, 115-125$

SCHNEIDER, S. M. (2003). Evolution, behavior principles, and developmental systems: A review of Gottlieb's Synthesizing nature-nurture: Prenatal roots of instinctive behavior. Journal of the Experimental Analysis of Behavior, 79, 137-152.

STOKES, A. W. (1967). Behavior of the bobwhite, Colinus virginianus. Auk, 84, 1-33.

Thomas, D. R., \& Switalski, R. W. (1966). Comparison of stimulus generalization following variable-ratio and variable-interval training. Journal of Experimental Psychology, 71, 236-240.

WALKER, D. J., \& Branch, M. N. (1998). Effects of variable-interval value and amount of training on stimulus generalization. Journal of the Experimental Analysis of Behavior, 70, 139-163.

WEARDEN, J. H., \& LeJEUNE, H. (2008). Scalar properties in human timing: Conformity and violations. Quarterly Journal of Experimental Psychology, 61, 569-587.

WeIsS, S. J., \& SCHINDLER, C. W. (1981). Generalization peak shift in rats under conditions of positive reinforcement and avoidance. Journal of the Experimental Analysis of Behavior, 35, 175-185.

WiLliams, B. A. (1973). The failure of stimulus control after presence- absence discrimination of click-rate. Journal of the Experimental Analysis of Behavior, 20, 23-27.

\section{NOTES}

1. That is, equal increments in the interval between each pulse (e.g., $1 \mathrm{sec}$ ) are perceived as equivalent along the generalization test spectrum, resulting in a gradient that would be symmetrical for pulses separated by $3 \mathrm{sec}, 4 \mathrm{sec}, 5 \mathrm{sec}$, and so on. Alternatively, equal rate differences might be the basis, with symmetrical results at 10,20 , and 30 pulses per minute, for example. Differently shaped gradients result. In the present study, the tempo difference between Interbeep Interval 5 and Interbeep Interval 6 was substantially larger ( 24.1 beeps per minute) than that between Interbeep Interval 2 and Interbeep Interval 3 (13.6 beeps per minute).

2 . Any body part of the same or greater thickness intercepting the photobeams could set them off, because no response pressure was required. However, observation during pilot testing verified that chicks pecked the targets, as would be expected following an autoshaping procedure.

3 . The disruption to the rhythm of the stimulus was minor: The training stimulus sounded at 188 beeps per minute, and few chicks pecked more than 20 times per minute. In addition, most pecks were reinforced, resulting in the feedback relay click.

4. Starlings have been shown to be capable of discriminating temporal gaps as short as $3.2 \mathrm{msec}$ under some conditions (Klump \& Maier, 1989).

(Manuscript received March 13, 2008; revision accepted for publication July 19, 2008.) 